\title{
The Modeling of Cross Flow Runner With Computational Fluid Dynamics on Microhydro Tube
}

\author{
Purwanto $^{{ }^{*}}$, Budiyono ${ }^{2}$, Hermawan $^{3}$, Sudarno $^{4}$ \\ ${ }^{1}$ Environmental Sciences, Postgraduate School, Diponegoro University, Semarang Indonesia \\ ${ }^{2}$ Diponegoro Vocational University, Semarang Indonesia \\ ${ }^{3}$ Department of Electrical Engineering, Diponegoro University, Semarang Indonesia. \\ ${ }^{4}$ Environmental Sciences Postgraduate School, Diponegoro University, Semarang Indonesia
}

\begin{abstract}
The Model of Fluid Dynamics Computation (CFD) aims to obtain cross-tubine flow in microhydro tubes. The parameters used to determine the cross flow turbine power are the blade angle, the number of cross runner blades and the head tube as the production house. Computational Fluid Dynamics (CFD) is software that can load integral and partial equations into discrete algebraic equations (addition, multiplication, multiplication and division) that can be used with the help of computers to find solutions for sources and times. In the era of technology, the development of the Computational Fluid Dynamics (CFD) program is very fast making this method a trend in various fields of industry that utilizes a comparison of pure experimental data and pure theory. The study of turbine cross flow power on microhydro tubes shows 1213 Watt power on the parameters of blade number 16 , blade angle of $15^{0}$ and $20^{\circ}$ at head 4 meters.
\end{abstract}

Keywords: Runner, Cross Flow, Computational Fluid Dynamics (CFD)

\section{Introduction}

Microhydro power plant with turbine cross flow becomes attractive because its construction is simple, easy, low maintenance costs, is a clean and environmentally friendly energy source, and has a good future development. Turbine cross flow construction consists of two parts namely nozzle and runner [9]. Turbine Cross flow was originally designed and patented by Australian Engineers in 1903. Then the results of his work were further developed by Donat Banki which was presented in a series of publications in 1917 and 1919. Banki work produce operating theory and experimental results about flow which show an efficiency of $80 \%$ [7]. Theoretical and experimental research on flow characteristics and cross flow turbine performance to produce high turbine power is assisted by the Computational Fluid dynamics (CFD) method [1]. The power generated by the

\footnotetext{
${ }^{*}$ Corresponding author : pwtmhkd@yahoo.com
} 
turbine is an important factor in a micro-hydro power plant with a tube as a power house in determining production efficiency. Computational Fluid dynamics (CFD) provides an accurate analysis to be able to produce efficient power in turbine cross flow [8]. The principles are used with three basic laws, namely the law of conservation of time, Newton's second law/conservation law of momentum and energy conservation law. These three laws are expressed in mathematical equations which in the form of integral or differential equations become discrete algebraic equations (addition, subtraction, multiplication and division) that are possible to be worked on by computer programs [2]. This method is also becoming a trend especially the special new renewable energy sector it is related to fluid / fluid analysis examples for gas turbines, wind turbines and water turbines.

The development of this analysis is supported by the results of experimental tests using computational fluid dynamics as a tool for modeling, estimating, and analyzing turbine crosflow behavior under different operating conditions, with Computational Fluid dynamics (CFD) software using ANSYS-Fluent 18.0 [8]. Computational fluid dynamics to determine the turbine power by treating different models with blade number parameters, blade runner angle, and generator head [10].

\section{Method}

Microhydro Installation Analysis with a tube as a powerhouse uses water energy as an energy source to drive a turbine runner. It is possible to set geometric parameters that affect turbine power is number of blades, blade runner angle and generator head [5]. The construction of the power plant as follows:

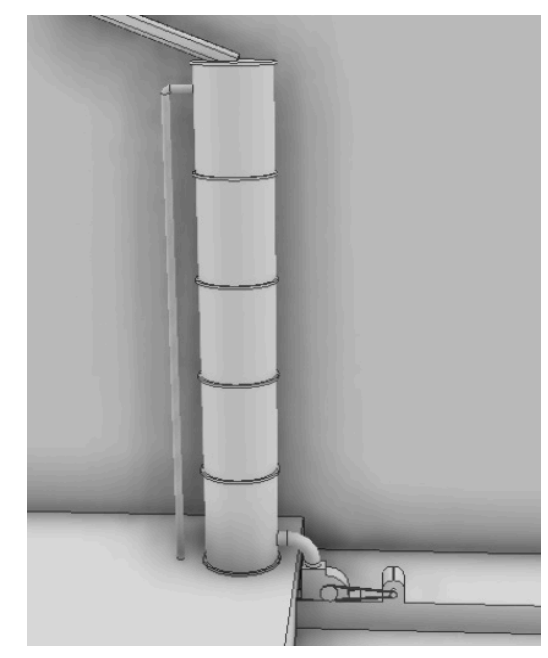

Fig. 1. Microhydro Tube Generator

\subsection{Components of Microhydro Tube Generators}

- Intake serves to direct water into the tube made of PVC pipe / permanent construction.

- $\quad$ Tube (Calm) functions to store water that is while before being discharged through a machine (turbine) as a generator house (tube).

- Overflow channel functions to channel water into the generator house (tube) in order to maintain the stability of the electricity gap. 
- The engine (turbine) as the generator is chosen as the flow type because it has suitable characteristics (discharge, head and power house).

- Exhaust channel, this channel serves to direct the water that comes out of the turbine so as not to damage the power plant location.

\subsection{Theory of Computational Fluid Dynamics (CFD)}

The Computational Fluid dynamics (CFD) method is an art of making changes in the equation of fluid dynamics in derivative and integral forms into discrete algebraic forms (addition, subtraction, multiplication and division) that can be solved by computer programs. The development of Computational Fluid dynamics (CFD) technology can be utilized as a complement to pure theoretical and experimental data. Computational Fluid dynamics (CFD) theory can also function as a research tool that is becoming a trend in the world of engineering design because of its flexibility and ease in finding trends in relation to one parameter to another parameter. There are three governing equations in fluid dynamics, namely continuity equations, equations, momentum and energy equations as follows [4]:

Equation for continuity of integral forms,

$\frac{\partial}{\partial t} \iiint_{V} \rho d V+\iint_{A} \rho \vec{V} \cdot d \vec{A}=0$

Equation for continuity of diverential forms,

$$
\frac{\partial \rho}{\partial t}+\rho \vec{\nabla} \cdot \vec{V}=0
$$

The equation of momentum in the direction of the $\mathrm{x}$ axis,

$$
\frac{\partial(\rho u)}{\partial t}+\vec{\nabla} \cdot(\rho u \vec{V})=-\frac{\partial p}{\partial x}+\frac{\partial \tau_{x x}}{\partial x}+\frac{\partial \tau_{y x}}{\partial y}+\frac{\partial \tau_{z x}}{\partial z}+
$$

$\rho f_{x}$

The equation of momentum in the direction of the y axis,

$$
\frac{\partial(\rho v)}{\partial t}+\vec{\nabla} \cdot(\rho v \vec{V})=-\frac{\partial p}{\partial y}+\frac{\partial \tau_{x y}}{\partial x}+\frac{\partial \tau_{y y}}{\partial y}+\frac{\partial \tau_{z y}}{\partial z}+
$$

$\rho f_{y}$.

The equation of momentum in the direction of the $\mathrm{z}$ axis,

$$
\frac{\partial(\rho w)}{\partial t}+\vec{\nabla} \cdot(\rho w \vec{V})=-\frac{\partial p}{\partial z}+\frac{\partial \tau_{x z}}{\partial x}+\frac{\partial \tau_{y z}}{\partial y}+\frac{\partial \tau_{z z}}{\partial z}+\rho f_{z} \cdots \cdots \cdots
$$

The energy equation is written in the form of internal energy,

$$
\frac{\partial}{\partial t}\left[\rho\left(e+\frac{V^{2}}{2}\right)\right]+\vec{\nabla} \cdot\left[\rho\left(e+\frac{V^{2}}{2}\right) \vec{V}\right]=\rho \dot{q}-\frac{\partial(\rho p)}{\partial x}-\frac{\partial(v p)}{\partial y}-\frac{\partial(w p)}{\partial z}+\rho \vec{f} \cdot \vec{V}
$$


The solution of partial differential analytical equations results in the continuous dependent form dependent variable expression across all domains. Conversely, numerical equation solutions can only give values at discrete points in a domain, also called grid points.

\subsection{Geometry}

In the industrial world Computational Fluid dynamics (CFD) software is developing rapidly and rapidly not only for strength analysis and structural deflection but is often also carried out in determining the optimal configuration based on fluid interactions with turbines. Computational Fluid dynamics (CFD is very popular in solving problems related to mechanics complicated and complex fluid [2]. So in the geometry using a simulation that represents the fluid model (negative) of the rotor and fluid volute. This model is divided into two parts, namely the stator portion of the stationary part and the rotating part of the rotor to facilitate the movement of the rotor:

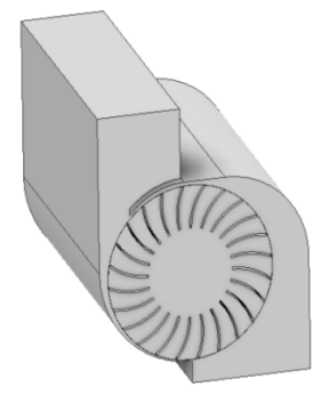

Fig. 2. Model Geometry

\subsection{Meshing / Grinding}

Meshing is a process of discretization (addition, subtraction, multiplication and division of fluid domains which continuously become discrete computational domains so that fluid flow equations can be completed / worked on and produce a solution by numerical methods [3]. The following is the result of meshing / grinding of simulated models below this:

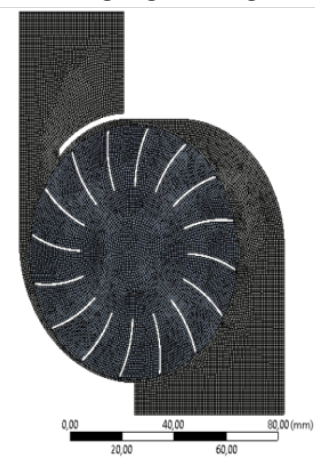

Fig. 3. Meshing/Grinding Results 


\section{Result}

The following are the computational settings used in the simulation to produce solutions to the problems of fluid mechanics in turbine crossflows in microhydro tube plants [6]. This volume of fluid model is used for two fluids which have different density as in water and air. This simulation presents a fluid model with the following settings:

- Rotor: in this domain use the following settings: ( Water material, rotating, gravity direction -9.81 towards $\mathrm{z}$, reference density $=1000 \mathrm{~kg} / \mathrm{m} 3$ and domain initialization patch, with water volume fraction $=1$ )

- Static: in this domain some settings are used as follows: ( Water material, static, gravity direction -9.81 towards $\mathrm{z}$, reference density $=1000 \mathrm{~kg} / \mathrm{m} 3$ and domain initialization patch, with air volume fraction $=1$ )

- Inlet Total pressure (stable) $=$ Adjust head : ( Input is the inlet pressure that represents the head pressure used on the generator in this case $=4 \mathrm{~m})$

- Out Put $=0 \mathrm{~Pa}$ : (At the outlet for settings as the reservoir of the flow so that it is expected that all the flow out of the outlet.)

- Number of Iterations: 1000 : ( The number of iterations is based on a residual graph and the unchanged flow distribution of additional iterations (depending on converging conditions) this process is done every 1000 iterations repeatedly).

Simulations can be taken to produce data in the form of volume distribution fraction of water that presents the flow patterns that occur in the turbine. 
3.1 Distribution of water volume fraction at $15^{\circ}$ blade angle with 16 bladecounts and $4 \mathrm{~m}$ generating head

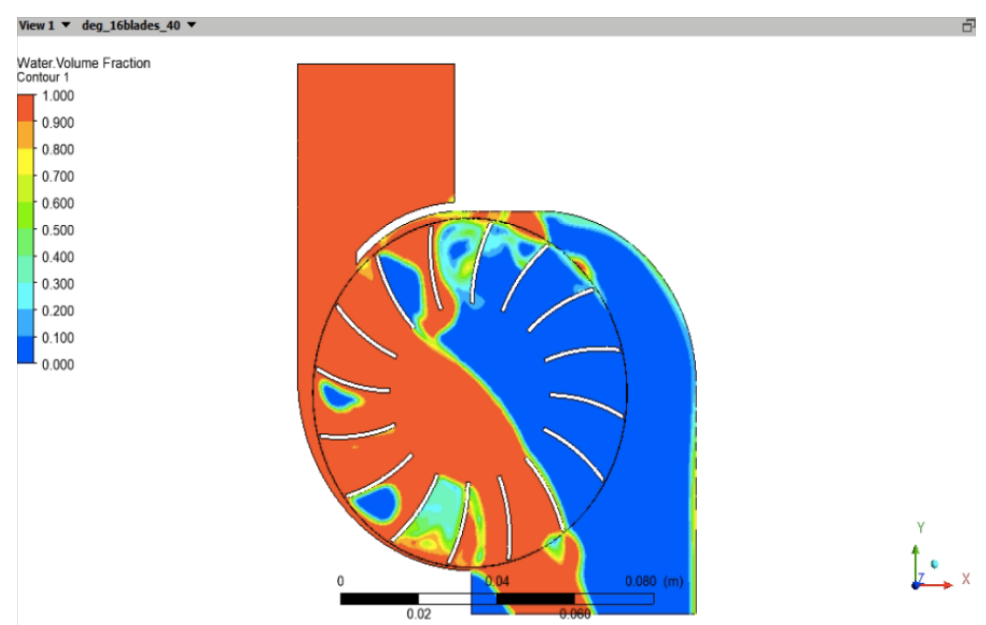

Fig. 4. Faction distribution of head air volume $4 \mathrm{~m}$.

3.2 Distribution of water volume fraction at a blade angel of $20^{\circ}$ with the number of blades 16 and $4 \mathrm{~m}$ generating head

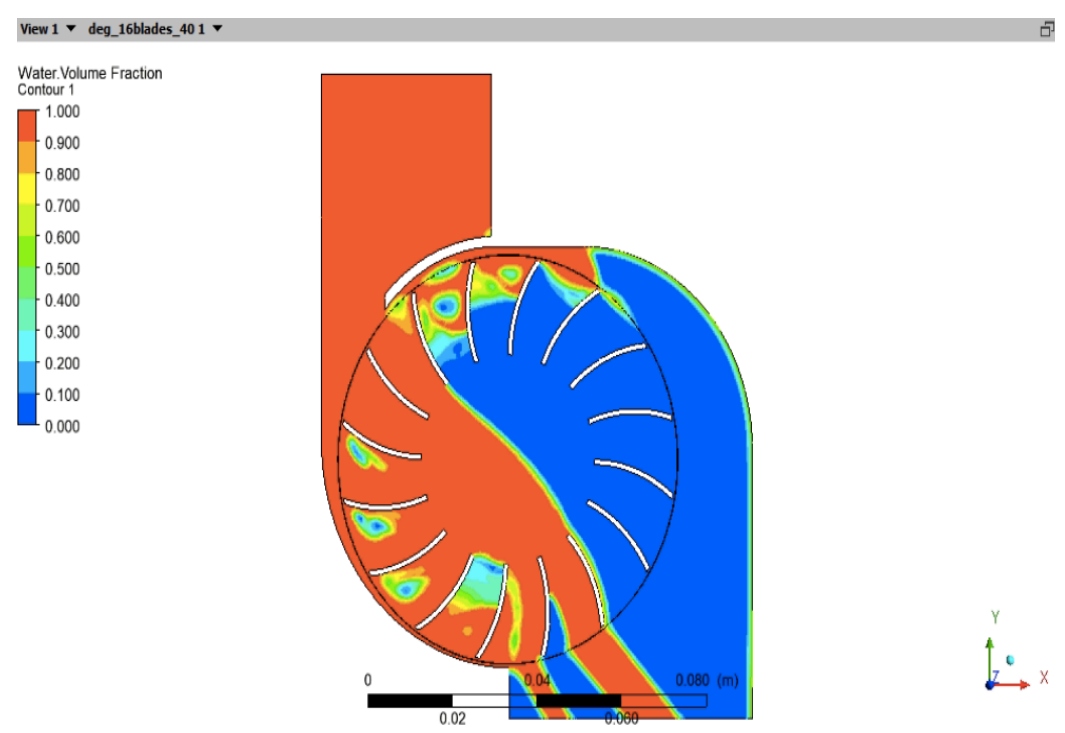

Fig. 5. Faction distribution of head air volume $4 \mathrm{~m}$. 
3.3 Distribution of water volume fraction at blade angle $15^{\circ}$ with blade number 20 and generator head $4 \mathrm{~m}$

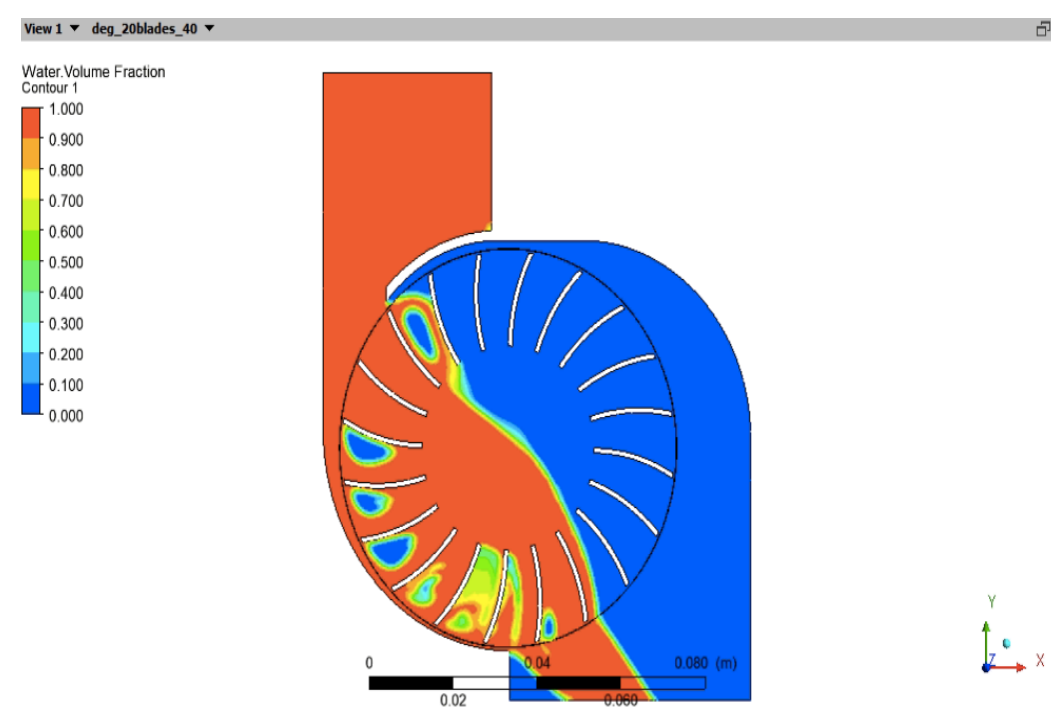

Fig. 6. Faction distribution of head air volume $4 \mathrm{~m}$.

3.4 Distribution of water volume fraction at $20^{\circ}$ blade angles with 20 blade counts and $4 \mathrm{~m}$ generating head

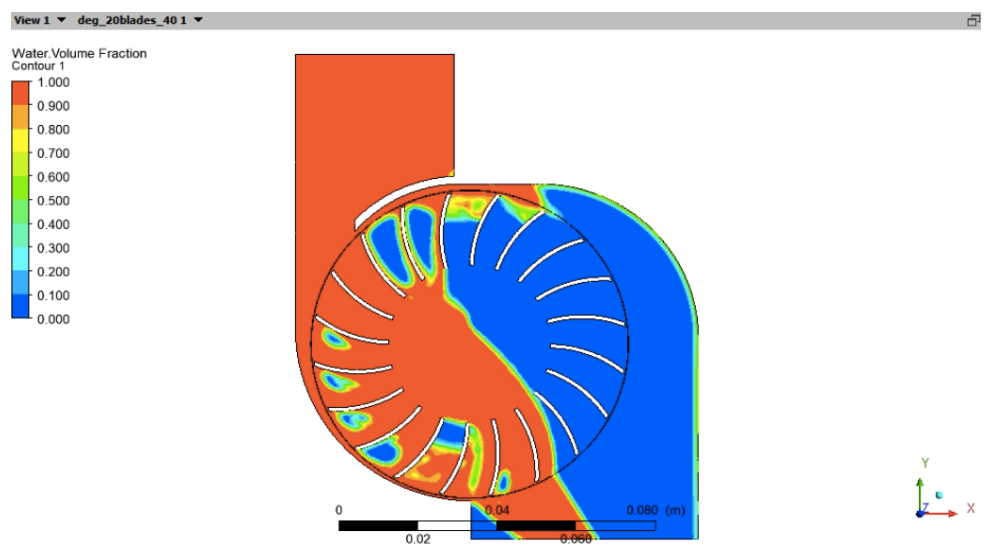

Fig. 7. Faction distribution of head air volume $4 \mathrm{~m}$. 
3.5 Distribution of water volume fraction at blade angle $15^{\circ}$ with blade number 24 and generator head $4 \mathrm{~m}$

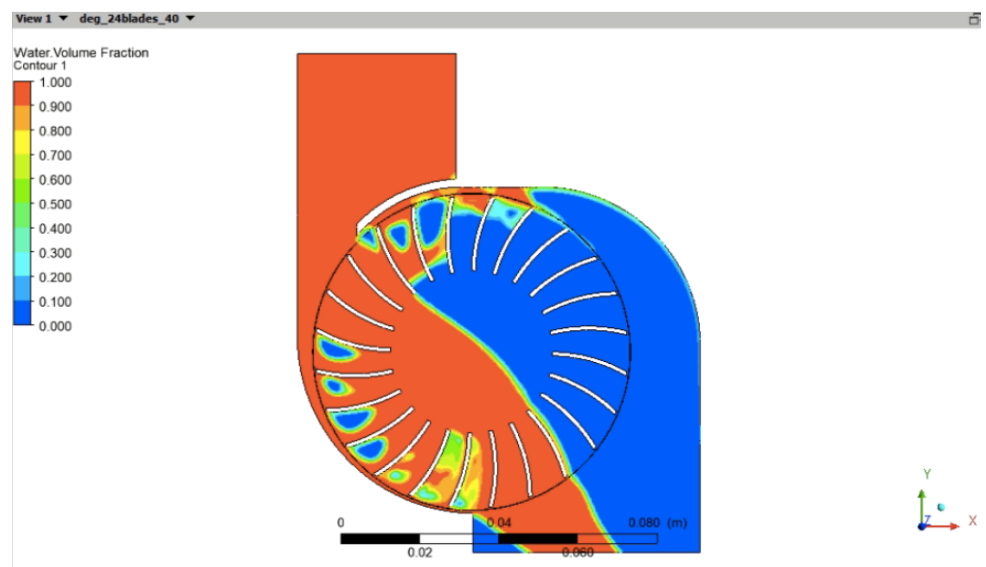

Fig. 8. Faction distribution of head air volume $4 \mathrm{~m}$

3.6 Distribution of water volume fraction at blade angle $20^{\circ}$ with blade number 24 and generator head $4 \mathrm{~m}$

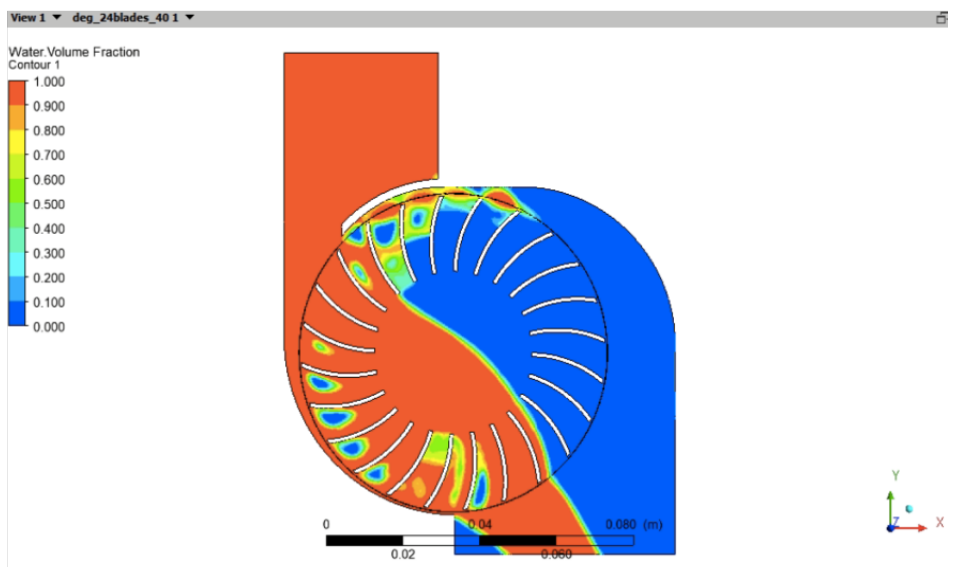

Fig. 9. Factional distribution of head water volume $4 \mathrm{~m}$

\section{Data on Results of Conversation}

Measurement and analysis of data to characterize turbine behavior with $15^{\circ}$ and $20^{\circ}$ blade angle parameters, number of blade runners and tube generator head. So that it will produce charts and curves as follows: 
Table 1. Measurement torque data in each case:

\begin{tabular}{|c|c|c|c|c|}
\hline Angle (deg) & Blades & Head (m) & Torque (N.m) & Power (Watt) \\
\hline \multirow{12}{*}{15} & \multirow{4}{*}{16} & 2.5 & 1.94444 & 203.5848124 \\
\hline & & 3 & 4.44452 & 465.3456885 \\
\hline & & 3.5 & 7.89501 & 826.615442 \\
\hline & & 4 & 11.5894 & 1213.421769 \\
\hline & \multirow{4}{*}{20} & 2.5 & 1.47976 & 154.9323518 \\
\hline & & 3 & 1.65263 & 173.0320136 \\
\hline & & 3.5 & 5.64644 & 591.1879144 \\
\hline & & 4 & 7.79871 & 816.5327357 \\
\hline & \multirow{4}{*}{24} & 2.5 & 1.20668 & 126.3406027 \\
\hline & & 3 & 3.58641 & 375.5007134 \\
\hline & & 3.5 & 6.30671 & 660.3188437 \\
\hline & & 4 & 9.10878 & 953.6983748 \\
\hline \multirow{12}{*}{20} & \multirow{4}{*}{16} & 2.5 & 2.31569 & 242.4550587 \\
\hline & & 3 & 5.39971 & 565.3550367 \\
\hline & & 3.5 & 8.52377 & 892.4472428 \\
\hline & & 4 & 9.16223 & 959.2946432 \\
\hline & \multirow{4}{*}{20} & 2.5 & 1.29821 & 135.9238852 \\
\hline & & 3 & 4.41744 & 462.5103854 \\
\hline & & 3.5 & 7.43686 & 778.6466789 \\
\hline & & 4 & 11.0972 & 1161.887937 \\
\hline & \multirow{4}{*}{24} & 2.5 & 2.11231 & 221.1609693 \\
\hline & & 3 & 4.62373 & 484.1091547 \\
\hline & & 3.5 & 7.48923 & 784.1298702 \\
\hline & & 4 & 10.6037 & 1110.217994 \\
\hline
\end{tabular}




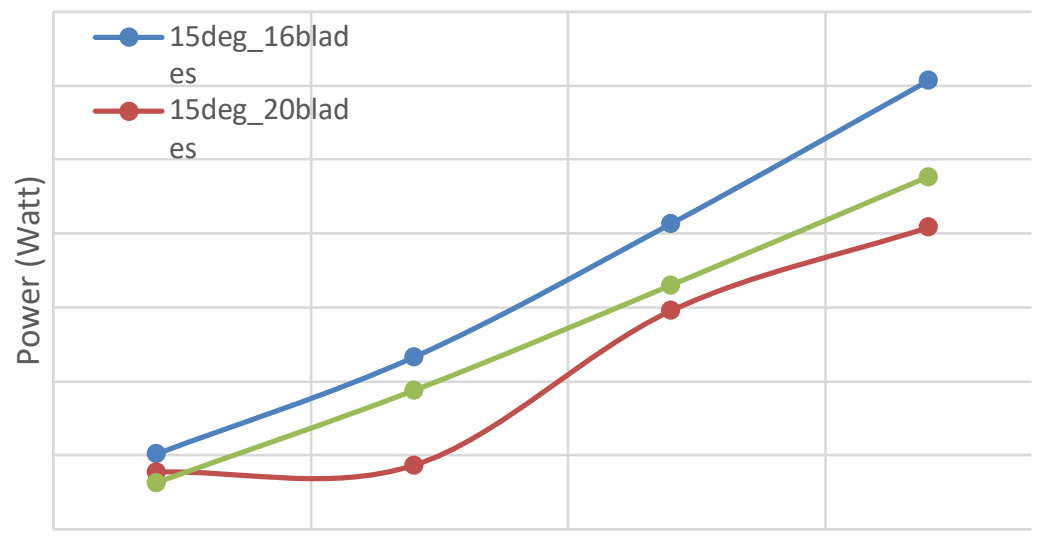

Head (m)

Graph 1. Power graph of head at $15 \mathrm{deg}$

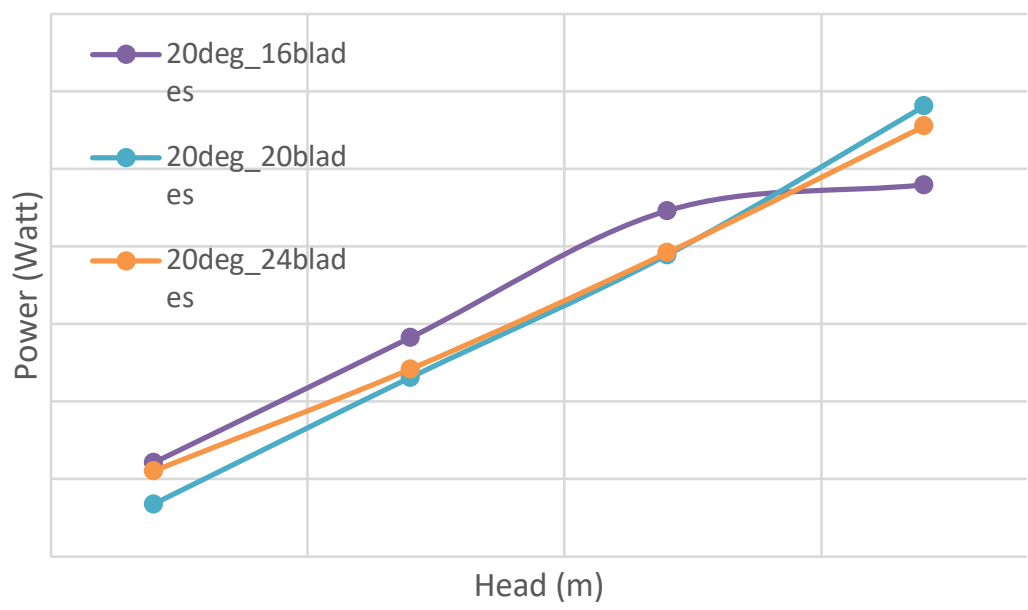

Graph 2. Power graph of head at $20 \mathrm{deg}$ 


\section{Conclusions}

The result showed that it can be seen that there is a non-linear relationship between the relationship of the power produced with the number of blades at an angle of $15 \mathrm{deg}$. The highest power produced occurs at 16 blades, then 24 blades and the lowest at 20 blades.

There is a trend that is almost the same at an angle of $20 \mathrm{deg}$ with $15 \mathrm{deg}$, is the highest power occurs in the number of blades 16, then $24 \mathrm{deg}$ and the lowest in the number of 20 blades. Then it can be concluded that the number of runners 16 , angle $15^{\circ}$ and $4 \mathrm{~m}$ head yields the highest power of 1213 Watt.

\section{References}

1. Abbott et al, Computational Fluid dynamics - An Introduction for Engineers. New York: Wiley (1989)

2. Wilcox, D.C et al. Turbulence Modeling For Computational Fluid Dynamics, La Canada, CA: DCW Industries, Inc (1998)

3. Bartosiewicz et al. Numerical And Experimental Investigations On Supersonic Ejectors, Int. J. Heat Fluid Flow, vol.26, pp.56-70 (2005)

4. Tu, J et al, Computational Fluid Dynamics: A Practical Approach (1 St Ed.). Amsterdam; Boston: Butterworth-Heinemann (2008)

5. Choi et al, Performance Improvement Of A Cross-Flow Hydro Turbine By Air Layer Effect (2010)

6. A.L. Andi, H. Syukri, S. Arifin., Manufacture and Testing of the 200 Watt Turbine Banki Power Micro Hydro Power Plant. Mechanical Journal, Volume 3 No. 01 (2012)

7. S. Saryazdi, and M. Boroushaki. 2D Numerical Simulation and Sensitive Analysis of $H$ Darrieus Wind Turbine. International Journal of Renewable Energy Development, vol. 7, no. 1, pp. 23-34, (2018)

8. V. Summartano, C. Arico, A. Carravetta, O. Fecarotta, T. Tucciarelli, Cross-Flow (BankiMichell) Optimal Design By Computational Fluid Dynamics Testing And Hydrodynamic Analysis, ISSN 1996-1073, Energies (2013)

9. W. Beabpimai, and T. Chitsomboon. Numerical Study of Effect of Blade Twist Modifications on the Aerodynamic Performance of Wind Turbine. International Journal of Renewable Energy Development, vol. 8, no. 3, pp. 285-292, (2019).

10. Soenoko R. First Stage Cross Flow Turbine Performance. International Journal Of Applied Engineering Research. Volume 11, No.2 pp 938-943. Research India Publications (2016) 